\title{
Submammary placement of neurostimulator devices: broadening the spectrum of cosmetic techniques
}

\author{
Ilias G. Petrou ${ }^{1}$ (D) $\cdot$ Shahan Momjian ${ }^{2} \cdot$ Ali Modarressi $^{1}$ \\ Received: 5 March 2020 / Accepted: 26 March 2020 / Published online: 21 April 2020 \\ (C) The Author(s) 2020
}

\begin{abstract}
Deep brain neurostimulators (DBS) have enabled thousands of individuals to overcome movement disorders, thus offering them a new chance for social integration while enhancing their self-esteem. A classic DBS consists of a central implantable pulse generator (IPG) and its respective wires and leads that extend to the scalp to reach the brain. The classic positioning of the generator is currently subcutaneous, usually just below the clavicle or in the abdominal wall. As DBS systems are of a substantial size, this subcutaneous placement leads to unsightly and visible devices, particularly in thin patients. We report two cases of female patients who benefited from our technique to hide the IPG under the breast parenchyma. IPGs were placed through an inframammary incision in a subglandular pocket, similar to the technique used for implant-based breast augmentation. In the first case, the devices were implanted in a subglandular pocket and replaced 5 years later due to battery life limitation. In the second case, the devices were replaced from a subclavicular position to a submammary one. No major or minor complications were observed. Both patients reported an excellent level of satisfaction with the aesthetic and functional outcome. Despite the significant quality of life improvement of patients with DBS, the ideal implantation of the generator should also take into consideration the comfort and cosmetic aspects. Our approach has the potential to markedly improve the aesthetic outcome of such an intervention.

Level of evidence: Level V, therapeutic study.
\end{abstract}

Keywords DBS $\cdot$ Neurostimulator $\cdot$ Scar $\cdot$ Cosmetic $\cdot$ Breast

\section{Introduction}

Deep brain stimulation (DBS) has become a commonplace procedure over the past decades for the management of Parkinson's disease [1], primary dystonia [2] or tremor [3], thus improving tremendously the patients' quality of life. The important success of this procedure has led to the further investigation of diseases that could be treated by DBS, such as treatment-resistant obsessive-compulsive disorder [4], epilepsy $[5,6]$ or even obesity [7]. DBS stimulates specific deep regions of the brain through one or two electrodes implanted

Ilias G. Petrou

ilias.g.petrou@gmail.com

1 Department of Plastic, Reconstructive, Aesthetic Surgery, Geneva University Hospitals, 4 Rue Gabrielle-Perret-Gentil, 14, 1211 Geneva, Switzerland

2 Division of Neurosurgery, Geneva University Hospitals and University of Geneva Faculty of Medicine, Geneva, Switzerland in the brain and controlled by a pacemaker-like apparatus called implantable central pulse generator (IPG). The device is usually inserted in a subcutaneous pocket just below the clavicle or in the abdominal region next to the umbilicus. It is connected to the intracerebral electrodes by a subgaleal and subcutaneous extension wire. To adjust the stimulation settings (e.g. appropriate pulse width, amplitude and frequency), a transcutaneous device is applied over the generator [8]. There are different IPGs stimulating one or two leads, either rechargeable or non-rechargeable. Non-rechargeable devices, particularly those driving two wires, are bulkier than the rechargeable ones as they must generate energy for several years until their replacement.

Several patient-related factors determine the choice of the best type of device and its anatomical placement. Patient habits (incorporation or not of the recharge session into their life) and preferences, including their body mass index (BMI), influence the decision.

Abdominal implantation is favoured for single large stimulators with two wires inputs, but it is subject to more 
complications (e.g. migration, disconnection). The subclavicular position has more advantages in terms of adverse events, but as a large IPG can be very visible and uncomfortable, smaller single-lead stimulators are placed, one in each side. However, in thin patients, even the smallest nonrechargeable devices may cause cosmetic and functional inconvenience. To overcome this problem, other positions have been described as the axillary or the submammary ones $[9$, 16]. In this report, we present our technique of implanting the generator in a subglandular pocket, such as the one used in implant-based breast augmentation (Fig. 1).

\section{Case Presentation}

DBS implantation in the submammary position was performed in two female patients. In the first patient, the device was implanted directly in a submammary position, while in the second one, we changed the position from a subclavicular to a submammary one.

Patient 1 was a 61-year-old woman (BMI, $23.5 \mathrm{~kg} / \mathrm{m}^{2}$ ) suffering from Parkinson's disease. In 2014, two unilateral non-rechargeable IPGs were placed in bilateral submammary pockets. Five years later, the same approach was used to replace the devices due to battery discharge. The operation time was $75 \mathrm{~min}$ for the initial placement and $45 \mathrm{~min}$ for the replacement procedure.

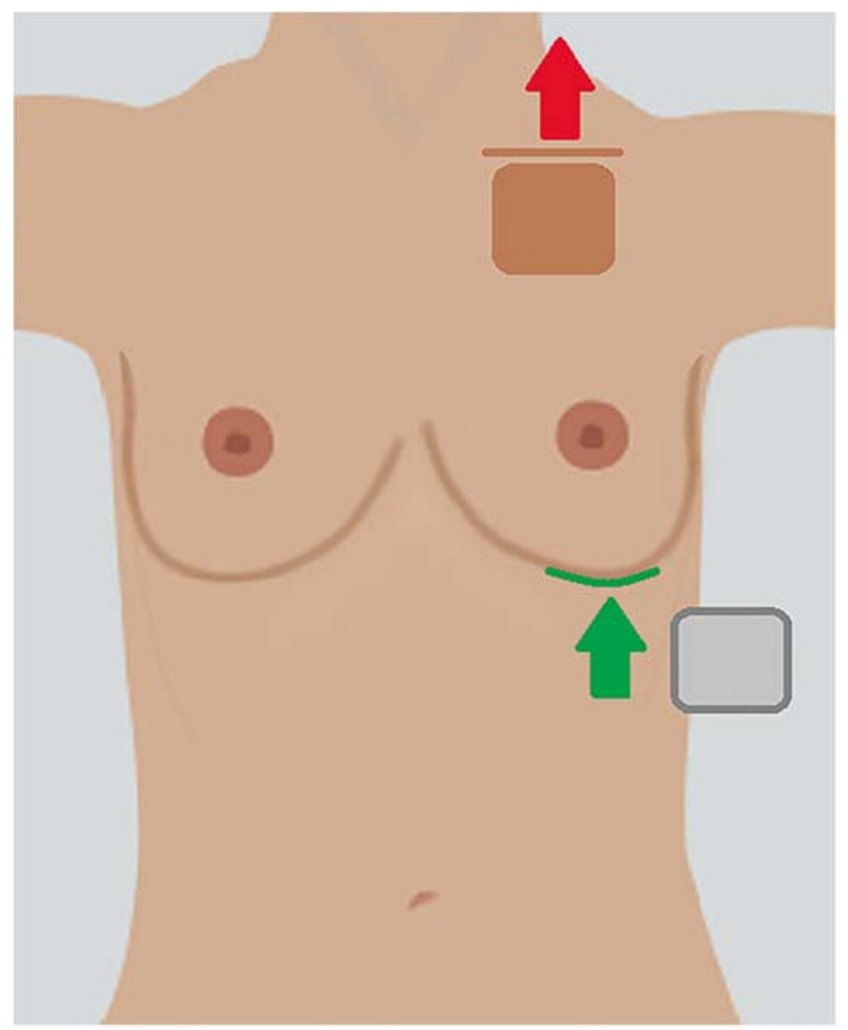

Fig. 1 Illustration of position change of IPG
Patient 2 was a 67 -year-old woman (BMI, $19.1 \mathrm{~kg} / \mathrm{m}^{2}$ ) who had two unilateral non-rechargeable IPGs in a subclavicular position for Parkinson's disease since 2013. In January 2018, she required device replacement. As the patient was unhappy with the aesthetic appearance and presented skin irritation because the devices were just below her brassiere straps, we proposed a bilateral submammary position.

\section{Surgical technique}

The surgical approach was similar to that of a subglandular implant-based breast augmentation via the inframammary fold. Subglandular dissection was performed with a standard surgical knife or a pulsed electron avalanche knife (PEAK) (PlasmaBlade ${ }^{\mathrm{TM}}$, Medtronic, Dublin, Ireland) [10] between the fascia of the pectoralis major muscle and the breast parenchyma. As soon as the IPG could fit into its new pocket, the neurosurgeons connected the device by passing the lead extensions in a subcutaneous manner. In patient 1 where the placement was made for the first time, the wires were passed directly all the way to the breast region, while in patient 2 , they were carefully extended from their previous subclavicular position. After the connection, transcutaneous verification was done to ensure that the device was functioning properly and the generator could be calibrated transcutaneously. The subglandular pocket was then closed with Vicryl ${ }^{\mathrm{TM}} 2.0$ (Ethicon, Somerville, NJ, USA) separate sutures to secure the gland to the inframammary fold, followed by skin closure.

Post-operatively, patients were instructed to avoid heavy lifting for 4 weeks, as well as wearing brassieres that could cause discomfort. They were also advised to rest and use their upper extremities as comfortable. First-level analgesia was prescribed, and patients were treated on an ambulatory basis. No major or minor complications were observed. Both patients reported excellent levels of satisfaction with the aesthetic outcome and intervention experience (Figs. 2, 3 and 4). The

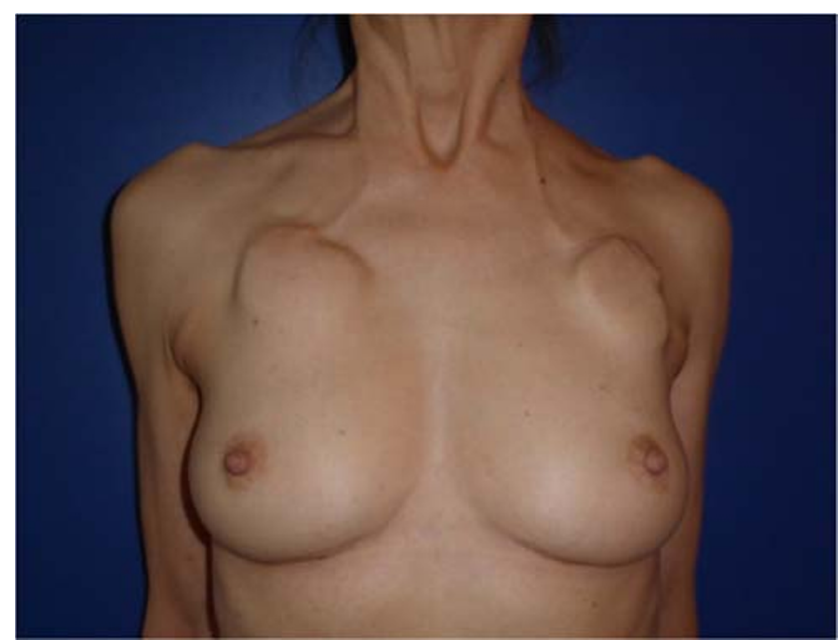

Fig. 2 Patient 2: Before the intervention 


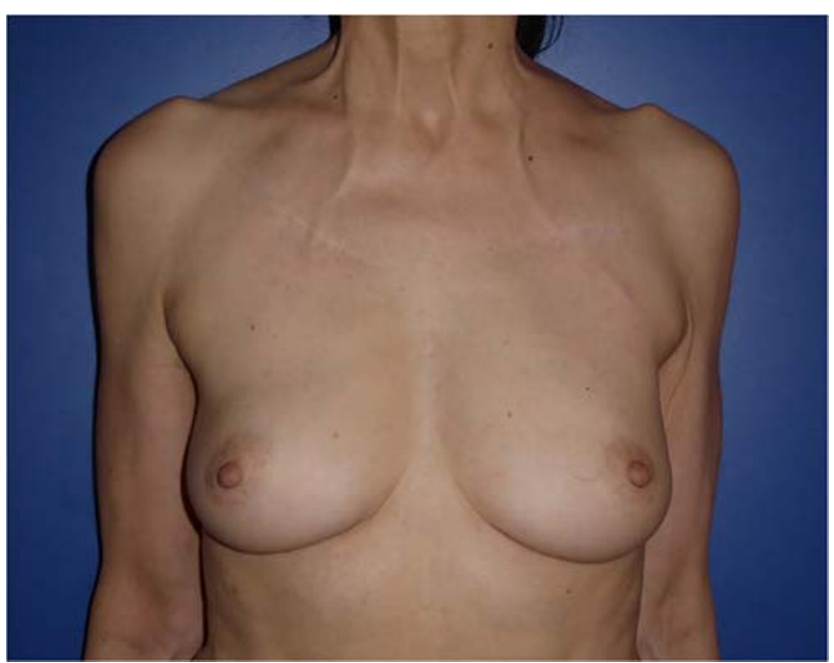

Fig. 3 Patient 2: 18 months after position change, anterior view

second patient affirmed that she would have opted for a submammary position from the beginning if it had been possible. Both patients gave their informed consent for the use of their medical data and photographs.

\section{Discussion}

Although DBS offers satisfactory results and improves quality of life by decreasing motor dysfunction [11], some patients are concerned about the poor aesthetic appearance and discomfort of the subcutaneous implantation of IPGs [12]. Even though IPG position cosmesis in female patients has gained attention the recent years, we should point out that this problem has been already addressed more than 30 years ago [13] for cardiac pacemaker positioning, where the submammary approach is shown to achieve satisfactory cosmetic results [14].

As a result, alterative novel positions to the classic subclavicular and abdominal ones have been reported lately

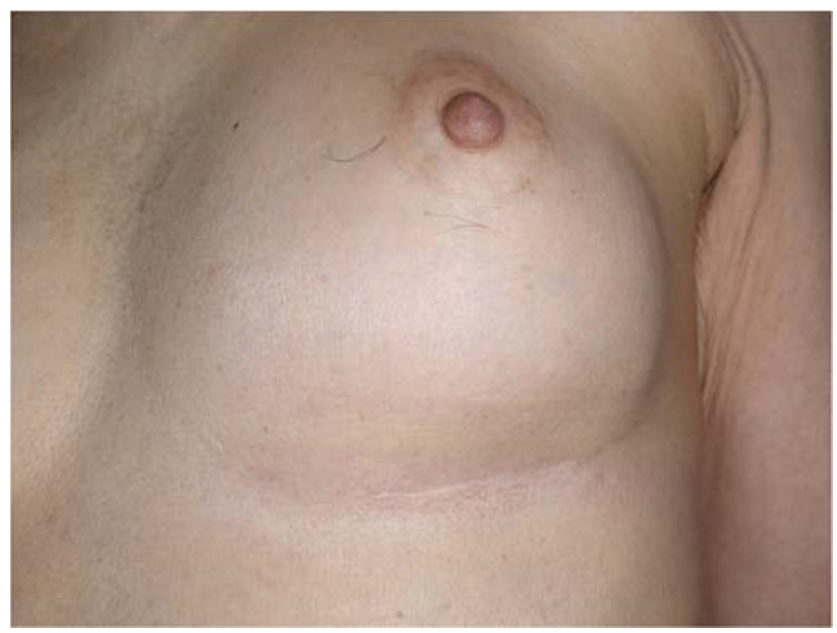

Fig. 4 Patient 2: Insertion scar at 18 months post-operatively with a specific interest in the submammary $[15,16]$ and the transaxillary [9] approach. However, the reports in the literature are limited with no comparative study between the different methods.

In the hands of an experienced plastic surgeon, the dissection of a submammary pocket is easy and safe with limited complications. When compared in a theoretical point of view with the axillary placement under the pectoralis muscle, it can be easily understood that the submammary approach holds various advantages. Since our submammary technique requires only a subglandular pocket with no detachment of the pectoralis major muscle, we can expect lower complications rates and lower post-operative pain. Moreover, the position just above the fascia of the pectoralis major muscle and below the mammary gland offers sufficient tissue in order to anchor the device.

IPG replacement has been shown to hold a relatively high complication rate with infection as the most frequent one and mostly in the subcutaneous thoracic position [17]. Although we did not observe any infections in our patients, the limited number of our cases cannot provide safe conclusions.

Despite the fact that IPG submammary placement can give very aesthetically satisfying results $[15,16]$, there are some limitations of the technique. First, the surgeon must ensure that the termination of the extension wires will reach the new submammary position. In our particular cases, we did not have any problems to reach the desired position, but the consistent use of $90-\mathrm{cm}$ wires over the $60-\mathrm{cm}$ ones could easily address the issue. Second, as the devices are controlled in a transcutaneous manner, the overall subcutaneous and glandular thickness that covers the generator can be a concern. For example, the maximum soft tissue thickness acceptable above the Medtronic Activa SC (Medtronic, Dublin, Ireland) generator is $5 \mathrm{~cm}$. Therefore, a careful preoperative evaluation and patient selection is crucial to avoid such a problem. Third, for surgeons who are unfamiliar with breast surgery, the dissection could be more difficult and time-consuming than the subclavicular or abdominal position. The initial presence of an experienced plastic surgeon could facilitate the process since it is an easily learnable operation. Furthermore, in the case of IPG replacement, the submammary scar tissue surrounding the wires could become bothersome. We recently replaced two IPGs without any difficulty. We should mention that the use of a PEAK PlasmaBlade ${ }^{\mathrm{TM}}$ (Medtronic, Dublin, Ireland) that is based on radiofrequency soft tissue dissection and protects from generator and wire damage was helpful. Lastly, since the devices are placed under the breast parenchyma, there are obvious concerns about the breast cancer screening. Although mammography could be difficult to execute, breast ultrasound or MRI imaging could be proposed as in our patients after placement. The close collaboration with specialized radiologists and the awareness of this operation are of crucial importance in order to achieve an uneventful breast cancer screening. 
Even if there is a current trend towards the primoimplantation of small rechargeable neurostimulators in the subclavicular position, some patients will still request nonrechargeable generators that are less costly and do not need frequent recharge. We consider that these patients and those already with subclavicular non-rechargeable generators could greatly benefit from submammary implantation. However, comparative high-quality trials are needed to confirm our findings and to affirm the ideal IPG position.

Clinicians should be aware of the important role of aesthetic appearance in candidates for DBS implantation. In particular, for female patients, the submammary placement of the device should be considered as it is a safe and easy procedure. This innovative approach can drastically improve the cosmetic appearance and comfort in selected patients.

\section{Funding None}

\section{Compliance with ethical standards}

Conflict of interest Ilias G. Petrou, Shahan Momjian and Ali Modarressi declare that they have no conflict of interest.

Ethical approval The research meets all applicable standards with regard to the ethics of experimentation and research integrity.

Informed consent Informed consent was obtained from all individual participants included in the study.

Open Access This article is licensed under a Creative Commons Attribution 4.0 International License, which permits use, sharing, adaptation, distribution and reproduction in any medium or format, as long as you give appropriate credit to the original author(s) and the source, provide a link to the Creative Commons licence, and indicate if changes were made. The images or other third party material in this article are included in the article's Creative Commons licence, unless indicated otherwise in a credit line to the material. If material is not included in the article's Creative Commons licence and your intended use is not permitted by statutory regulation or exceeds the permitted use, you will need to obtain permission directly from the copyright holder. To view a copy of this licence, visit http://creativecommons.org/licenses/by/4.0/.

\section{References}

1. Krack P, Batir A, Van Blercom N et al (2003) Five-year follow-up of bilateral stimulation of the subthalamic nucleus in advanced Parkinson's disease. N Engl J Med 349(20):1925-1934

2. Coubes P, Roubertie A, Vayssiere N, Hemm S, Echenne B (2000) Treatment of DYT1-generalised dystonia by stimulation of the internal globus pallidus. Lancet. 355(9222):2220-2221

3. Schuurman PR, Bosch DA, Bossuyt PM, Bonsel GJ, van Someren E, de Bie RM, Merkus MP, Speelman JD (2000) A comparison of continuous thalamic stimulation and thalamotomy for suppression of severe tremor. N Engl J Med 342(7):461-468
4. Greenberg B, Gabriels L, Malone D et al (2008) Deep brain stimulation of the ventral internal capsule/ventral striatum for obsessivecompulsive disorder: worldwide experience. Mol Psychiatry 15: 64-79

5. Fisher R, Salanova V, Witt T, Worth R, Henry T, Gross R, Oommen K, Osorio I, Nazzaro J, Labar D, Kaplitt M, Sperling M, Sandok E, Neal J, Handforth A, Stern J, DeSalles A, Chung S, Shetter A, Bergen D, Bakay R, Henderson J, French J, Baltuch G, Rosenfeld W, Youkilis A, Marks W, Garcia P, Barbaro N, Fountain N, Bazil C, Goodman R, McKhann G, Babu Krishnamurthy K, Papavassiliou S, Epstein C, Pollard J, Tonder L, Grebin J, Coffey R, Graves N, SANTE Study Group (2010) Electrical stimulation of the anterior nucleus of thalamus for treatment of refractory epilepsy. Epilepsia. 51(5):899-908

6. Koeppen JA, Nahravani F, Kramer M et al (2018) Electrical stimulation of the anterior thalamus for epilepsy: clinical outcome and analysis of efficient target. Neuromodulation. 22:465-471

7. Whiting AC, Sutton EF, Walker CT, Godzik J, Catapano JS, Oh MY, Tomycz ND, Ravussin E, Whiting DM (2019) Deep brain stimulation of the hypothalamus leads to increased metabolic rate in refractory obesity. World Neurosurg 121:e867-e874

8. Kochanski RB, Sani S (2018) Awake versus asleep deep brain stimulation surgery: technical considerations and critical review of the literature. Brain Sci 8:E17

9. Son BC, Han SH, Choi YS, Kim HS, Kim MC, Yang SH, Lee SW (2012) Transaxillary subpectoral implantation of implantable pulse generator for deep brain stimulation. Neuromodulation. 15(3):260 266 discussion 266

10. Loh SA, Carlson GA, Chang EI, Huang E, Palanker D, Gurtner GC (2009) Comparative healing of surgical incisions created by the PEAK PlasmaBlade, conventional electrosurgery, and a scalpel. Plast Reconstr Surg 124:1849-1859

11. Marras C, Lang A, Krahn M, Tomlinson G, Naglie G, Parkinson Study Group (2004) Quality of life in early Parkinson's disease: impact of dyskinesias and motor fluctuations. Mov Disord 19:2228

12. Messina G, Rizzi M, Dones I, Franzini A (2014) Cosmetic posterior implant of internal pulse generators in deep brain stimulation procedures: technical report. Neuromodulation. 17:729-730

13. Belott PH, Bucko D (1983) Inframammary pulse generator placement for maximizing cosmetic effect. Pacing Clin Electrophysiol 6(6): 1241-1244

14. Giudici MC, Meierbachtol CJ, Paul DL, Krupa RK, Vazquez LD, Barold SS (2013) Submammary device implantation in women: a step by step approach. J Cardiovasc Electrophysiol 24(4):476-479

15. Stroop R, Holms F, Nakamura M, Lehrke R (2018) A submammarian approach for cosmetically improved implantation of deep brain stimulation generators. World Neurosurg 109:e699 e706

16. Hong J, Ridgway EB (2015) Implantable pulse generator site pain treated with mastopexy and submammary placement. Neuromodulation: Technol Neural Interface 18:754-756

17. Narváez-Martínez Y, Roldán Ramos P, Hoyos JA, Culebras D, Compta Y, Cámara A, Muñoz E, Martí MJ, Valldeoriola F, Rumià J (2019) Single-center complication analysis associated with surgical replacement of implantable pulse generators in deep brain stimulation. Stereotact Funct Neurosurg 97(2):101-105

Publisher's note Springer Nature remains neutral with regard to jurisdictional claims in published maps and institutional affiliations. 